\title{
Introducing service robotics in in patient geriatric care-a qualitative systematic review from a human resources perspective
}

\author{
Anne-Katrin Haubold ${ }^{1}$ (D) - Lisa Obst ${ }^{1} \cdot$ Franziska Bielefeldt $^{1}$ \\ Published online: 18 August 2020 \\ (c) The Author(s) 2020
}

\begin{abstract}
This article in the journal Gruppe. Interaktion. Organisation. (GIO) presents a qualitative systematic review of nursing home staff perspectives on the usage of robotic devices in geriatric nursing. Robotic devices have been introduced to the field of inpatient geriatric care only recently. Although the elderly are seen as the primary users of many robotic devices in geriatric care, staff members are the driving force in the implementation and application of these devices. Hence, the Human Resources department has an important role to play in the introduction of service robotics in inpatient geriatric care. In the context of the present study, 22 empirical studies could be identified which were analysed based on the HR framework of Beer et al. (1984). Results hint at differences in staff perception of social robots and robots that support physical activities. Based on the discussion of the findings, five practical recommendations for the introduction of service robotics in inpatient geriatric care are made.
\end{abstract}

Keywords Service robotic $\cdot$ Geriatric care $\cdot$ Human resources management $\cdot$ Review

\section{Einführung von Servicerobotik in Einrichtungen der stationären Altenpflege - ein qualitativ-systematisches Review aus der Personalmanagement-Perspektive}

\section{Zusammenfassung}

Dieser Artikel in der Zeitschrift Gruppe. Interation. Organisation. (GIO) stellt ein qualitativ-systematisches Review vor zur Perspektive des Pflegepersonals auf den Einsatz von Robotern in der Altenpflege. Roboter wurden erst kürzlich in den Bereich der stationären Altenpflege eingeführt. Obwohl die älteren Menschen als Hauptanwender vieler Roboter in der Altenpflege gelten, sind die Beschäftigten die treibende Kraft bei der Implementierung und Anwendung dieser Geräte. Damit kommt der Personalabteilung eine wichtige Rolle bei der Einführung der Servicerobotik in der stationären Altenpflege zu. Im Rahmen der vorliegenden Studie konnten 22 empirische Studien identifiziert werden, die auf der Grundlage des HR-Rahmens von Beer et al. (1984) analysiert wurden. Die Ergebnisse deuten auf Unterschiede in der Wahrnehmung der Beschäftigten zwischen sozialen Robotern und Robotern hin, die körperliche Aktivitäten unterstützen. Aus der Diskussion der Ergebnisse werden fünf praktische Empfehlungen für die Einführung der Servicerobotik in der stationären Altenpflege abgeleitet.

Schlüsselwörter Service-Roboter $\cdot$ Stationäre Altenpflege $\cdot$ Personalmanagement $\cdot$ Review

\section{Introduction}

Prof. Dr. Anne-Katrin Haubold

haubold@htw-dresden.de

1 Arbeitsgruppe Human Factors and Resources, Hochschule für Technik und Wirtschaft Dresden (HTW), Friedrich-List-Platz 1, 01069 Dresden, Germany
Robots and robotic devices are entering the workplace at fast pace. But not every digital or electronic device is a robot; following the ISO standard 8373 (as of 2012), a robot can be defined as "an automatically controlled, reprogrammable, multipurpose manipulator programmable 
in three or more axes, which can be either fixed in place or mobile for use in industrial automation applications."

In industrial settings, robotic devices are to be found in many production sites (Steil and Maier 2018). Consequently, a larger amount of human factors research is available in this field, focusing especially on human-machine interaction in cyber-physical production systems (e.g., Nikolakis et al. 2019). In the service sector however, robots are still rare; this holds especially true for human-centered/ social services like nursing. In contrast to industrial settings, the workflow in human-centered services is less plannable and has a low potential for standardisation, since the work is not directed towards interchangable goods but towards idiosyncratic human beings. As a consequence, developing and implementing suitable robotic devices in the service sector is still a challenging undertaking (Rodeschini 2011).

Despite these challenges, there is a growing interest in social robots in the health-care sector. The majority of countries of the Western world are experiencing a shortage of skilled labour in nursing (Pammolli et al. 2012). Many hope that intelligent social robots will be able to partly compensate for this lack of nursing staff and the growing number of elderly in need of care (Darzi 2018); according to Darzi (2018, p. 27), introducing further digital technologies in the care sector could free up to $24 \%$ of care workers' time. In some countries, political action has been taken to support robotics investments in geriatric nursing organisations-as of beginning 2019, German nursing organisations are eligible to get a public refund for $50 \%$ of the investment costs for digital/robotic devices (German Ministery of Health 2018). In the United Kingdom, government has launched a $£ 34$ million research fund to trigger and support robotics research in the nursing field (UK Government 2019). Getting funding for this investment is one thing, but implementing robots in the nursing work environment is another thing. In contrast to industrial settings, ethical questions play an important role in the implementation of social robotics in the care sector, such as the question whether robots should be restricted to background work or be allowed to deal with an elderly person directly. Not surprisingly, nursing professionals' opinions about using social robots in nursing homes are not univocally positive, but the attitude seems to be influenced by national/cultural background: Coco et al. 2018; find significantly more positive attitudes in Japanese nurses compared to Finnish nurses.

It might be true that the introduction of service robots in geriatric nursing homes has achieved a high political and media attention recently, but the topic itself is not completely new. First empirical studies on the topic date back to the early 1990s (e.g., Mendell et al. 1991). With regard to the analytical approaches studied so far in this field, the portfolio ranges from the theory of action regulation (Hacker 1983) over the socio-technical systems approach (Trist and Bamforth 1951) to motivational approaches (Humphrey et al. 2007; for a comparison of all three approaches see Mlekus, Ötting, Maier 2018). In many organisations, it is the human resources (HR) department which is deeply involved in implementing new technology in the workplace. In this role, the HR department has to deal with certain practical issues which are not central to the psychological approaches mentioned above, such as: training existing personnel; recruiting new qualified staff; reallocating responsibilities, and informing employees about forthcoming changes. Therefore, the main research question for the current study is the following: What empirical evidence is available with regard to the role of the HR function supporting the employees in dealing with robotic devices in a geriatric nursing home context?

In order to structure the analysis, the classical Human Resources (HR) framework developed by Beer et al. (1984), later referred to as the Harvard Human Resources Management (HRM) framewok (Boxall 1992), will be used. The model has been chosen because it describes the influencing factors and consequences of HR work in a formal way. In this model, HRM policy choices are geared to the main stakeholder groups; stakeholder groups are considered as the first important influencing factor in the model. This orientation reflects the role of the HR department as an internal service provider. The model regards HRM activities as being oriented towards the current needs of an organisation, hence the second influencing parameter featured is the situational factor. Following the model, both the stakeholder groups and the current situational factors have an impact on which HR policies are chosen. Two types of consequences are covered by the model: Firstly, proximate consequences (HRM consequencess), namely the commitment of the employees, growth in competence, perceived congruence between employee skills and his/her work tasks, and finally the cost-effectiveness of HR policies. Secondly, also longterm consequences are included in the model which describe potential positive effects of HR policy choices on a higher level of abstraction such as organisational effectiveness. The authors of the model propose a causal chain from the influential factos to the long-term consequences with the latter having a recursive impact on the influencing factors.

Fig. 1 illustrates the set-up of Harvard HRM framework.

HRM policy choices Transferred to the current application case, the central question with regard to HRM policy choices is whether the introduction of a service robot changes the human resources flow and the task allocation, because certain tasks are then taken over by the robotic system. Another important policy aspect which might be subsumed under the term "work systems" is the aspect of competency management and training: The introduction of 


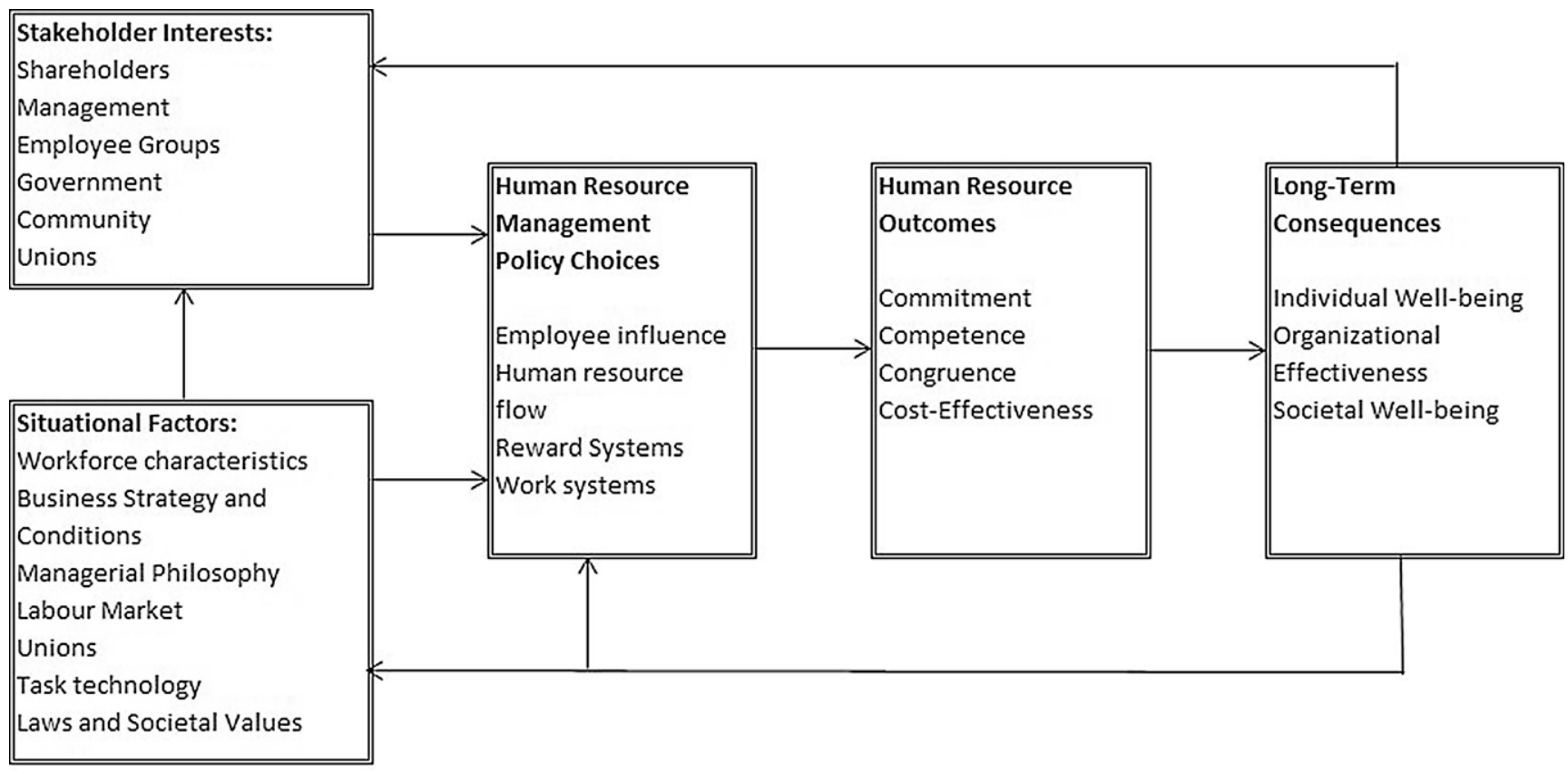

The Harvard Model of Human Resource Management

Fig. 1 The Harvard framework for Human Resource Management. Source: Beer et al. (1984)

service robotics in a geriatric nursing home setting might require more technical expertise among the employees; a competency gap of this kind can either be closed through training the existing staff or recruiting new employees.

Assumption 1 The introduction of robotics in the work context of a geriatric nursing home leads to new HRM policy choices with regard to the human resources flow as well as competency management and training.

Situational factos The central situational factor in the current case is task technology: In our applied context, it refers to the different kinds of service robots that can be implemented in geriatric nursing homes. But other situational factors might be of equal interest. For the health-care sector, the workforce characteristics are special in so far as the sector's workforce is known to be predominantly female and and to have a non-technical educational background. Also, laws and societal values might play an important role in health-care due to high ethical demands and personal responsibilities of each employee (Zwijsen et al. 2011).

Assumption 2 The situational factors technology, laws and societal values have an impact on HR policy choices in the work context of a geriatric nursing home that uses robots.

Stakeholder interests Of pivotal importance for the implementation of robotic devices in healthcare are obviously the interests of their primary users, the employees. However, since investment decisions are taken by the management, the attitude of the management board (and possible that of a supervisory board) might also have a significant impact on the implementation of service robots in geriatric nursing homes and what follows from it with regard to HRM.

Assumption 3 The interests of the employees and the management have an impact on HR policy choices in the work context of a geriatric nursing home that uses robots.

HR consequences In the logic of the Harvard model, adequate HR policies lead to positive consequences on the side of the employee. In the current case, the main question is whether changes can be perceived with regard to the HR consequences after a service robot has been introduced to the work system of a geriatric nursing home.

Assumption 4 The introduction of robotics in the work context of a geriatric nursing home leads to changes in HR consequences mediated by specific HRM policy choices.

Long-term consequences The ultimate goal of HRM efforts is to satisfy both organisationsal needs through achieving organisational effectiveness as well as individual needs by establishing individual (and, on the long run) societal wellbeing. This goal is coherent with the intentions of imple- 
menting service robots in the health-care sector (Decker 2008), as was described above.

Assumption 5 The introduction of robotics in the work context of a geriatric nursing home has long-term consequences mediated by specific HRM policy choices and HR consequences.

\section{Methodology}

In order to answer the research question above, a qualitative systematic review of the relevant empirical studies was executed. Following Grant and Booth (2009), a qualitative systematic review integrates and compares findings from—in our case: mainly—qualitative studies. The purpose of a qualitative systematic review is described by Grant and Booth (2009, p. 94) as follows: "It looks for 'themes' and 'constructs' that lie or across individual qualitative studies." The qualitative systematic review was chosen because an initial scoping of the literature had already revealed that a significant part of the empirical studies in question are qualitative by nature.

An extensive and comprehensive search for relevant studies was executed. Fig. 1 shows the procedure of the study selection. The systematic search using the search path *robot* AND ("residential care*" OR "elder* care*" OR "elder* care facilit*" OR "nursing home*" OR "long term care*" OR "geriatric care*" OR "geriatric nursing*" OR "old age care*" OR "retirement home*" OR "old age home*" OR "geriatric care facilit*") was carried out in nine databases: Scopus, EBSCO, PsycINFO, Pubmed, Medline, IEEE Explore, Science Direct, Sage Journals and Web of Science. Only peer-reviewed journal articles in English were taken into account. No time limit imposed due to the fact that research including robotic devices has gathered momentum only over the past two decades. Peer-reviewed conference papers were excluded from the search due to their restricted length and therefore expected lower level of detail. The studies identified by the database search were checked for duplicates and sorted out if the above inclusion criteria were not met. The abstracts of these publications were then subjected to a screening as part of a rough analysis and checked for compliance with the criteria. Studies describing, for example, only system components (e.g. language recognition) or individual aspects of robots (e.g. gripping function) or concentrating on home care or nursing in general were also excluded. In a next step, additional information was extracted from the full-text version of each study in order to check again the inclusion criteria mentioned above (focus on geriatric nursing homes, usage of complete robotic systems). This step was used to exclude further studies that did not meet

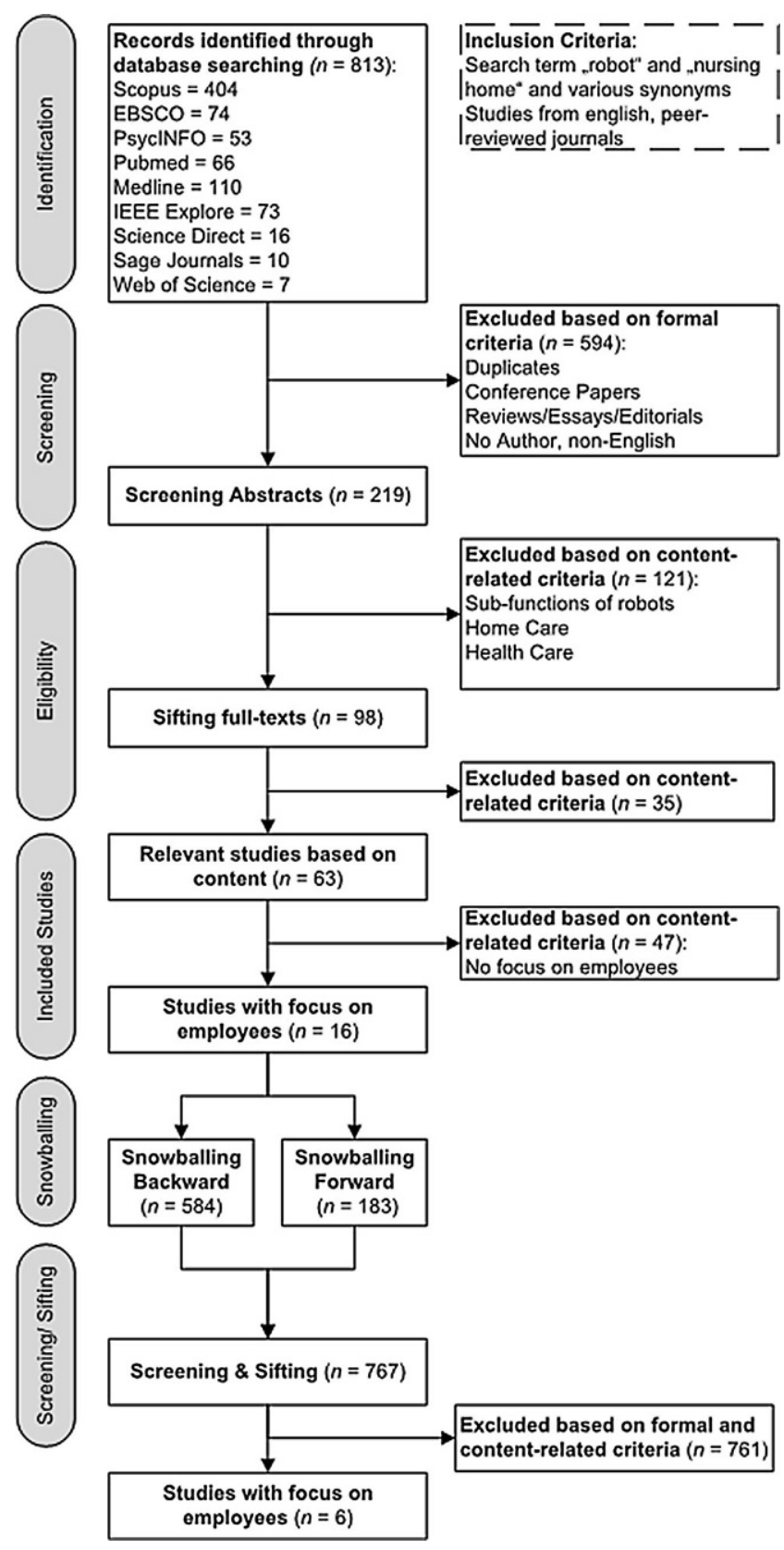

Fig. 2 Illustration of the literature search and selection process (own illustration)

the defined inclusion criteria. Of the remaining studies, 16 included data from members of staff. Based on this body of research, the number of relevant studies could be increased through snowballing backwards and forwards (Greenhalgh and Peacock 2005) to 22 altogether.

Fig. 2 illustrates the search procedure.

This body of 22 studies was then coded according to formal aspects (data collection method, size of sample, region of data collection) as well as content-related aspects (type of robot used, consequence variable, direction of effect). The coding was undertaken by two independent experts (the sec- 
ond and the third author of this publication). In those few cases where the coding results showed a lack of consensus were resolved in a subsequent discussion of the two coding experts; an interrater correlation was not calculated. Table 1 illustrates the coding results. The material was then handed over to the first author of this publication who then extracted additional information/'themes' from the publications with focus on the Harvard HRM framework.

\section{Results}

HRM policy choices/assumption 14 out of the 22 publications reviewed contain information on consequences of introducing the robotic device on the workflow: Robinson et al. (2016) asked the nursing staff who had been exposed to the robot Paro whether the robot did affect their job; 15 out of 21 members of staff answered "not at all"- the example comment reported by Robinson et al. (2016, p. 109) is: "Not much at all (too busy to use the robot)." In Wright's (2018) study on the usage of a robotic lifting device, the time needed to fetch and install the robot for usage is commented negatively by several employees: "Transfer robots are big and it is time-consuming to prepare it every time you use it. We can't use it in our current work routine." (Wright 2018, p. 32). In contrast, in the study of Bemelmans et al. (2016), the participating nursing staff used the robot Paro in 35 different care situations (e.g., wheelchair transport, activation); in 22 out of the 35 situations, the employees reported that the robot "added value" to the execution of the respective work task. What is special about this study is that each intervention was preplanned: Based on a work schedule planning, individually assigned interventions were conducted with pre-selected patients (Bemelmans et al. 2016, p. 156). Birks et al. (2016) report a case where a recreational therapist was confronted with a resident who was constantly and unnecessarily calling for help; she changed her usual work routines by letting the robotic seal Paro calm down the resident instead of doing this by herself.

With regard to competency management and training, again the study of Bemelmans et al. (2016) strikes out: Their intervention programme includes a 2 week blended learning training course for the nursing staff before letting them use the robot Paro. In other studies, the robotic devices are explained in a short introductory session.

Summarising the findings above, assumption 1 can only be partially supported: The introduction of robotics in the work context of a geriatric nursing home leads only in a minority of cases to specific HRM policy choices.

Situational factors/assumption 2 As Table 1 shows, there is only one technological device which is used in multi- ple studies - this is the robotic seal Paro. Paro is a soft toy which is socially responsive; it is a market-ready product since 2003. The soft toy is mainly used as a therapeutic tool especially for elderly people suffering from dementia; since Paro is used to calm elderly people-for example during transports in wheelchairs-or simply for entertainment: the animal-like sounds that the seal makes as soon as it is stroked or spoken to stimulate dementia sufferers to spend more time with Paro (Takayanagi et al. 2014). JustoCat and PaPeRo are comparable products, all belonging to the category of social robots whose main purpose is to interact with humans, hence taking over interactive activities from the caregiver. Far less studied robots are those that support physical activities like lifting, walking, bathing. As an important side note, Table 1 contains the duration of implementation which ranges from 3 "visits" of the robotic device in the nursing home to about a year of constant usage. In none of the 22 published studies, workforce characteristics like gender bias in caring professions or the skill mix of the employees have been discussed as situational factor. However, Gerling et al. (2016, p. 293) touch upon the issue by pointing out that a participatory design approach in robotic development is necessary in order to capture the needs of the health-care workforce. Three studies were found to mention legal and ethical issues as situational factors: Peronard (2013, p. 422) points out the vulnerability of nursing home residents and the risk of manipulating them; Wright (2018), whose study was published in an anthropological journal, describes in some detail legal and cultural factors that shape the appreciation of a lifting robot in Japan (which he found out to be limited, since staff rejects the lifting robot as it is considered disrespectful); Klein and Schlömer (2018) refer to the vulnerability of the elderly as a central situational factor and consequently put the ethical evaluation of the studied robotic shower system to the forefront of their research. Summarising these findings, the assumption can be supported that situational factors have an impact on the work context of a geriatric nursing home that uses robots; since HR policy choices are only explicitely addressed in 4 out of 22 studies, no conclusion can be drawn with regard to the direct impact of situational factors on HR policy choices in this research context.

Stakeholder interests/assumption 3 The interests of geriatric nursing home staff are treated in the majority of studies alike: The usual line of argumentation is that the introduction of service robots in geriatric care carries the chance to alleviate the shortage of skilled labour (e.g., Koceski and Koceska 2016; Peronard 2013; Moyle et al. 2016; Robinson et al. 2016, 2013; Bemelmans et al. 2013, 2016; Gerling et al. 2016; Erebak and Turgut 2018; Beedholm et al. 2015; Gustafsson et al. 2015; Bäck et al. 2013; Hebesberger et al. 


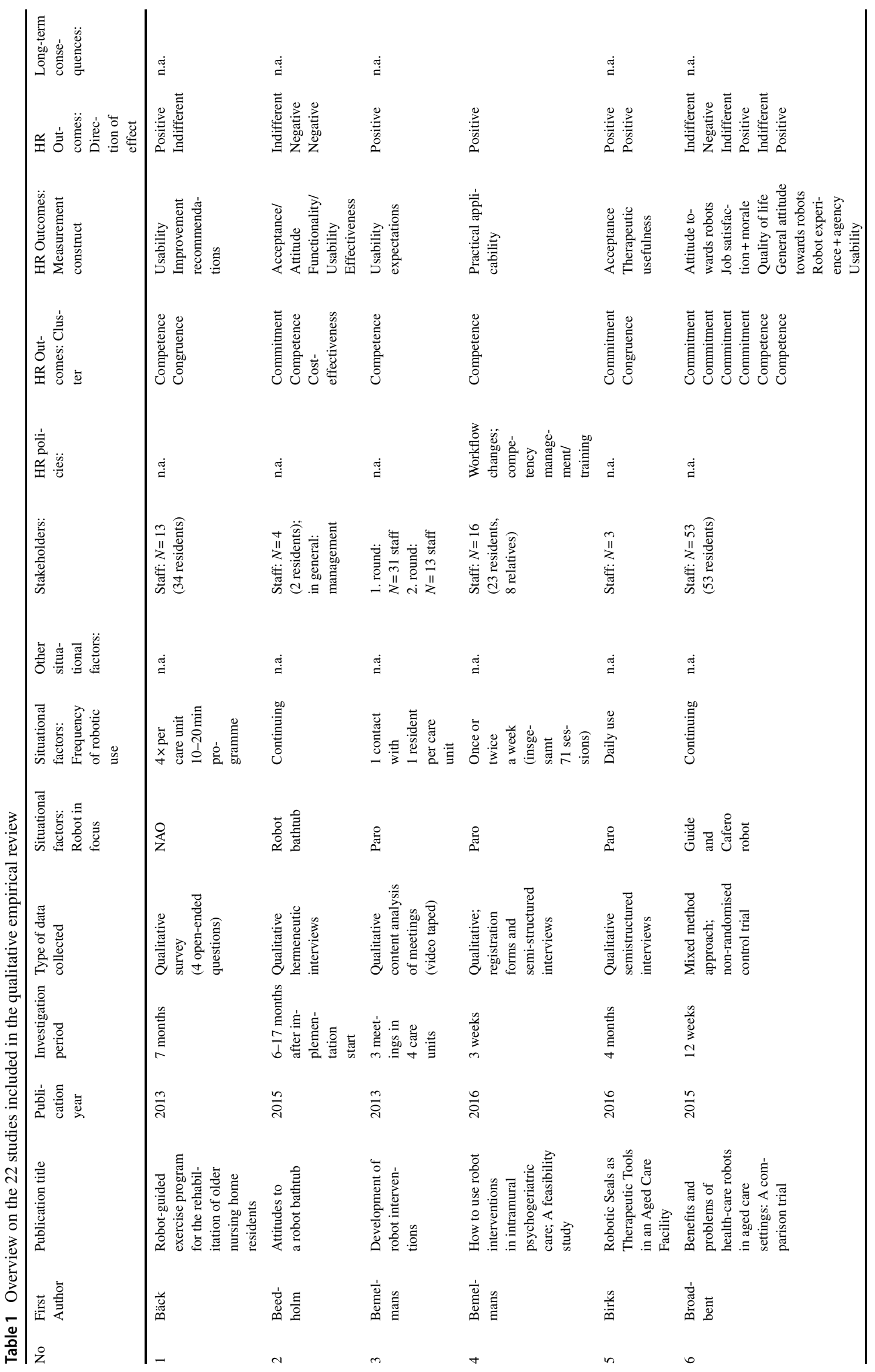




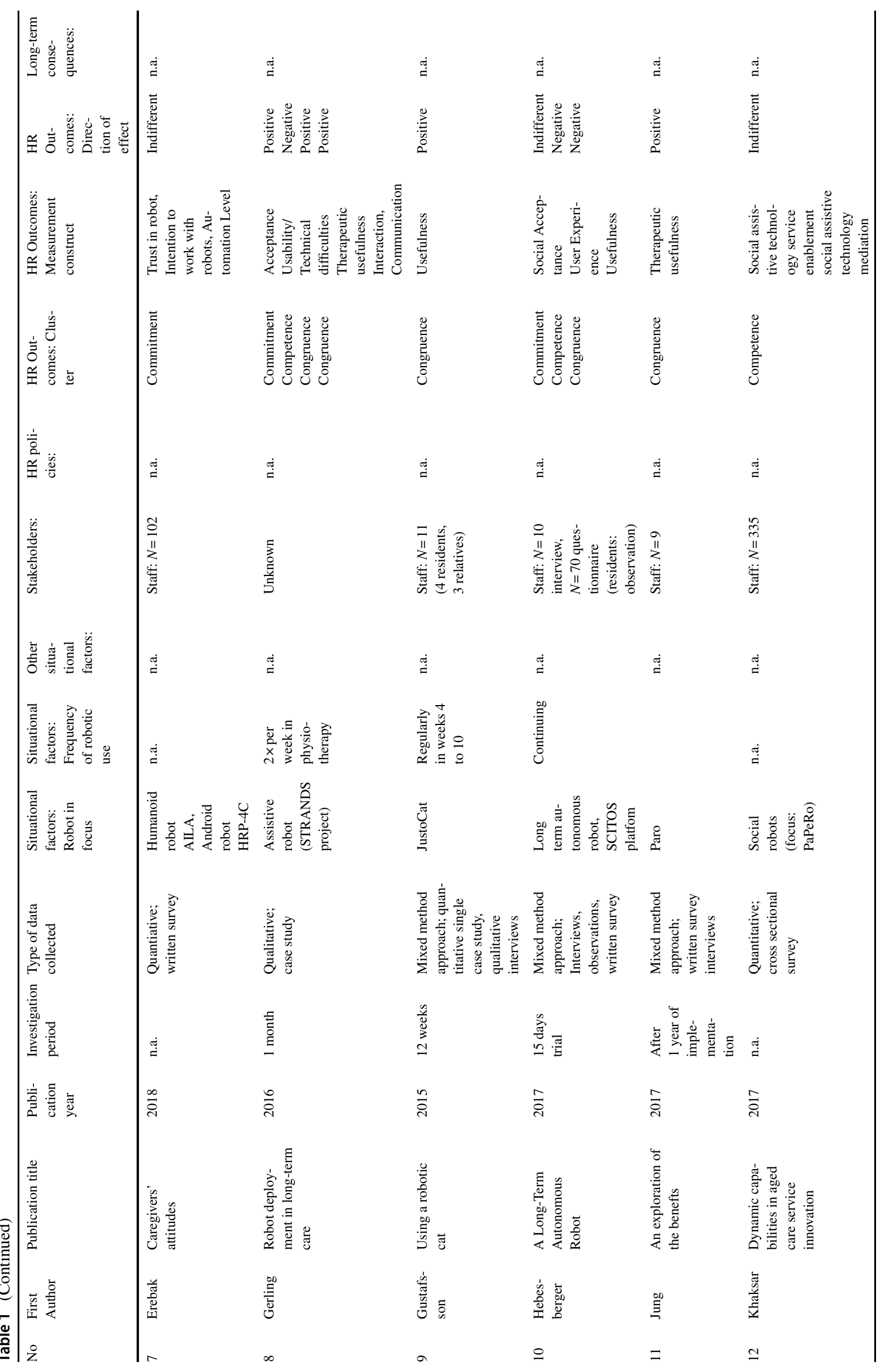




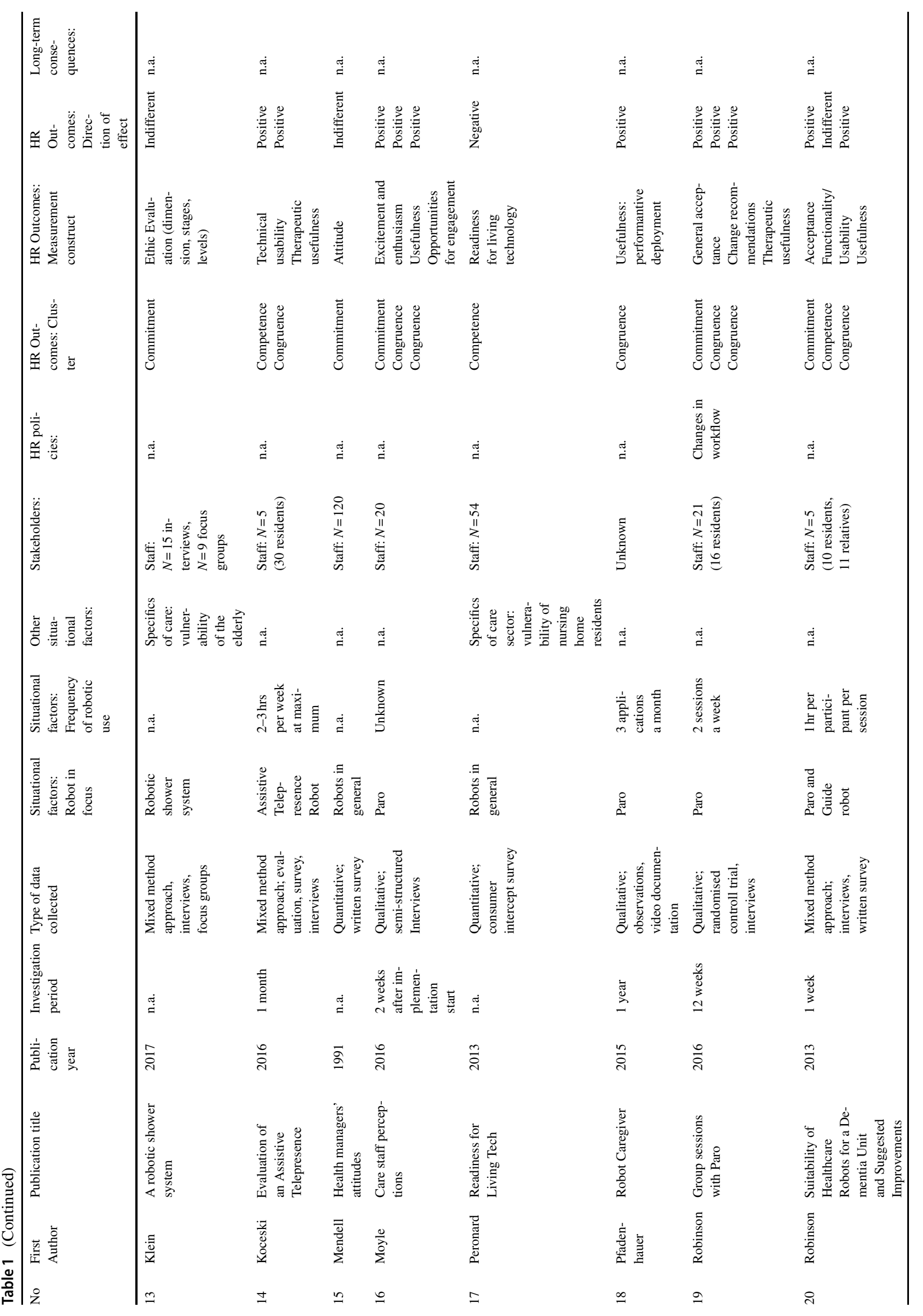




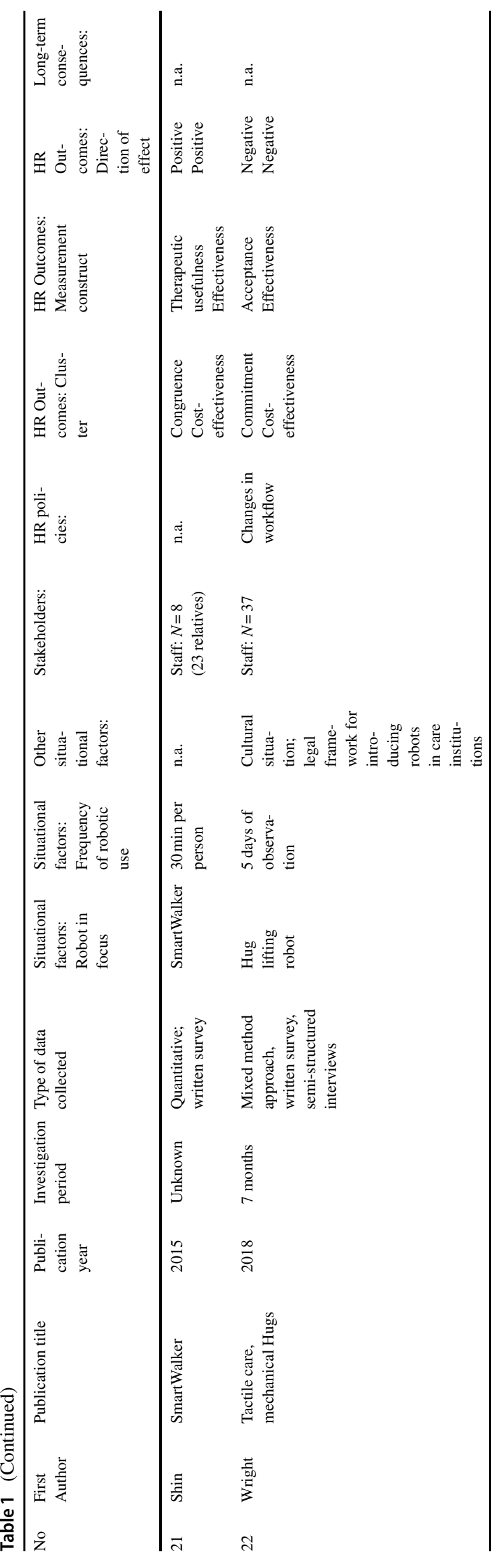

2017). A more in-depth analysis of the interests and motives of the nursing home employees is only to be found in the antrophologically-oriented study by Wright (2018): He pinpoints that the Japanese geriatric nurses in his study have an interest in creating a peaceful, relaxing atmosphere during the caring activities; they also have an interest in reducing the risk of suffering from backpain due to heavy lifting. The study of Beedholm et al. (2015) included the management's interest: They report that the manager who took the investment decision for a robot bathtub justifies the investment (despite the fact that the robot bathtub turned out not work properly) with a more general orientation towards innovation and business development (Beedholm et al. 2015, p. 282). The interests of other stakeholders like shareholders, or union representatives are not covered by any of the publications under scrutiny. Hence, it can be concluded that the interests of only some of the stakeholders (mainly the employees) have an impact on the work context, and to a very limited degree, of the HR policy choices of a geriatric nursing home that uses robots.

HR consequences/assumption 4 None of the studies covered measures commitment of staff as an consequence variable. However, the following attitudes are measured which might be regarded as prerequisites for commitment: acceptance of the robot, trust in the robot, the ethic evaluation of the robot, excitement and enthusiasm regarding the robot, general job satisfaction and morale as well as general quality of life. Out of the 15 effects in this consequence cluster, 6 are positive, 2 are negative and 7 are neutral or mixed. The subjective ratings of the usability/functionality of the robots can be regarded as an indicator for the second HR consequence variable in the Harvard model, competence: If the user perceives the robot as easy to handle, he/she most likely has the competence to handle the robot (and vice versa). Out of 12 effects in this consequence cluster, 5 are positive, 3 are neutral and 4 are negative. Another important consequence cluster is the perceived therapeutic usefulness of the robot as an indicator for the congruence between the task itself and the tools used to perform the task. 14 effects could be categorized as belonging to this cluster; 12 out of these are positive, one is neutral as it covers change recommendations, and one is negative. The last consequence variable mentioned in the Harvard HR model is cost-effectiveness. Three studies contain information on the effectiveness of implementing robots in geriatric care: Whilst Shin et al. (2016) report that staff expect the robot to be potentially time-saving, both Wright (2018) and Beedholm et al. (2015) report negative subjective ratings from staff regarding the effectiveness of using a robot.

Since a variety of robots are covered by the studies, two different groups of robots can be compared-social robots and robots that support physical activity. The social robot 
group of studies analyses interaction with robots like Paro, NAO, JustoCat, Guide, PaPeRo, while the studies associated with robots that support physical activities like the Scitos platform, Smart Walker, LiftingHug. As a result, in the social robots group, 17 out of $20 \mathrm{HR}$ consequence effects are positive and 3 are mixed or neutral and none show negative effects. For the studies of robots that support physical activity group, 8 out of 25 HR consequence effects are positive, 8 are mixed or neutral and 9 are negative.

In conclusion, the findings above support the assumption that the introduction of robotics in the work context of a geriatric nursing home leads to changes in HR consequences; as mentionned earlier, due to the limited availability of information, no statement can be made with regard to the role of specific HRM policy choices.

Long-term consequences/assumption 5 The 22 studies in focus do not report results with regard to the long-term individual well-being of the employees, the societal wellbeing or long-term organisational effectiveness. Hence the assumption cannot be supported that introducing robotics in geriatric nursing homes has recognizable long-term consequences.

\section{Discussion}

The findings presented above shed a light on the introduction of service robotics in inpatient care from a Human Resources perspective. With regard to the situational factors, the review provides interesting insights into the differences between the types of robots that can be used in inpatient geriatric care: While robots that support physical acitivites are associated with mixed HR consequences, social robots like Paro are linked to positive HR consequences. One possible explanation for this finding is the difference in handling: Since Paro, JustoCat, NAO and PaPeRo have the size of a soft toy, members of staff can carry them around easily - no changes in the work logistics are needed. On the contrary, robots that support physical activities are more difficult to move from one place to another, hence more time is needed for the caregiver to integrate the use of this device into the normal workflow. Another reason might be seen in the completeness of the tasks that can be taken over by the robots studied: Social robots take over entertainment and comforting tasks completely which allows caregivers the opportunity to concentrate on other activities. In contrast, lifting devices like the one studied by Wright (2018) can only be used by the direct supervision of a caregiver, and therefore cannot disencumber employees from a task completely. A third possible explanation for these findings could relate to the different development stages of the robotic device in use: While Paro is a mar- ket-ready product, the Scitos platform used by Hebesberger et al. (2017) for example is still in development.

Regarding stakeholder interests, the limited empirical evidence available (Wright 2018; Beedholm et al. 2015) hints at conflicts of interest between different groups of stakeholders, especially between management and staff. Geriatric nursing homes are in competition with each other; hence management might introduce robotic devices as a marketing means to attract new residents (Khaksar et al. 2017). The interests of the nursing staff will be shaped by the ANA Code of Ethics for Nurses or comparable national codes of ethics; the third provision of the ANA Code of Ethics for Nurses states: "The nurse promotes, advocates for, and protects the rights, health, and safety of the patient." (American Nurses Association 2015). Seen against this background, the introduction of robotic devices into inpatient geriatric care might evoke concerns regarding the violation of geriatric residents' rights and safety.

With regard to the policy choices of human resource management, the information that could be retrieved from the 22 empirical studies is remarkably sparse, as the results section shows. Assuming that the absence of information on changes in the policy choices reflects a real absence of changes in the HRM policies, the reason might be seen in the short exposure of the nursing staff to the robotic device: For example in the study of Bäck et al. (2013), the robot was used only 4 times for $10-20 \mathrm{~min}$. This piloting type of intervention might make nursing managers think that changes in work scheduling and work organisation as well as in-depth training is not necessary. However, as the study of Bemelmans et al. (2016) shows, a detailled training on how to use the robotic device in combination with preplanned intervention goals for each resident can lead to an intensive application of the robot in daily work routines.

As mentioned in the results section, the 22 studies in focus did not measure HR consequences like commitment or competence directly. The authors of these studies cannot be blamed for this, since they do not originate from the field of Human Resources Management and did not conduct their respective study with the Harvard HRM framework in mind. Nonetheless, as explained in the results section, the individual effects measured can be clustered along the HRM consequences of the Harvard model. However, as the results for the consequence cluster competence show, a lot of concerns are raised by the nursing staff with regard to the functionalities and the usability of the robotic devices. In a similar vein, the indicators for staff commitment as well as cost-effectiveness show mixed effects. In contrast to these findings, the therapeutic usefulness effects as an indicator for congruence are predominantly positive, meaning that nursing staff in general has a positive attitude towards robotic devices as a new element in working life. Put in a nutshell, this means that nursing staff does not oppose 
robotic devices per se, but critically reflects the concrete application of the devices. However, this critical reflection is not the same across all kinds of robots-as the comparision of social robots like Paro with robots that support physical activities shows, different types of robots seem to evoke different opinions by the staff.

With regard to the long-term consequences of robotic device deployment in inpatient geriatric care, the message is simple: Current studies do not allow for an outlook on what the introduction of robotic devices into inpatient geriatric care means for the future of the individual, the organisation and the society. An evident reason for this fact is the relative novelty of service robotics as a research field.

\section{Practical implications}

HR policy choices-recommendation 1 Assess the consequences the introduction of a service robot will have on different HR policies like workplanning, workflow management and staff training; develop and communicate respective policy changes well in advance. As has been outlined earlier, introducing robotic devices in inpatient geriatric care is a major undertaking which needs proper planning in order to be successful. However, the 22 studies considered here rarely report activities in the area of $\mathrm{HR}$ policies. As an exception from this general finding, Bemelmans et al. (2016, p. 156) propose an 11-step implementation procedure organised in three phases (training of care staff, selection of participants, conducting interventions) which might be taken as a starting point. In addition, as Cowan (2017) shows, the usage of change communication instruments might help to prepare employees for the expected changes in their work environment.

Situational factors-recommendation 2 Take the decision for or against the implementation of a robotic device by balancing strategic, ethical and human-oriented aspects. As part of the final decision, an analysis of the ethical implications of using a certain robotic device should be undertaken. Klein and Schlömer (2018) use the MEESTAR analytical model for this purpose; the MEESTAR model integrates three dimensions: On the $\mathrm{x}$ axis seven ethical aspects (care, autonomy, safety, justice, privacy, participation, self-conception), on the y axis four ethical judgement stages (from harmless to harmful), and on the $\mathrm{z}$ axis three perspectives (individual, organisational, social; Manzeschke et al. 2015). With regard to the human-oriented aspects, not only the characteristics of the residents should be taken into account, but also the workforce, team and organisational characteristics. Possible questions to ask include: Does the team possess the competence/technical skills necessary to operate the robotic device? Does the organisation have enough resources (in terms of manpower and execution time) in order to train staff to use the robotic device both in theory and practice?

Stakeholder interests-recommendation 3 Systematically explore stakeholder interests and integrate them into the implementation strategy. As the above discussion of stakeholder interests has indicated, different stakeholder groups might pursue different interests in this field. A stakeholder analysis (Savage et al. 1991) will help to understand where to find supporters and opponents for the implementation of service robotics in inpatient geriatric care. If the stakeholder analysis includes stakeholder interviews, this provides the opportunity to uncover unrealistic hopes or fears (robots will close the shortage of skilled labour in nursing/will take away all nursing jobs).

HR consequences-recommendation 4 Evaluate changes in the HR consequences systematically and holistically. As Table 1 shows, evaluative efforts most often only cover some few HR consequences. The four dimensions of the Harvard HR framework provide a meaningful basis for this evaluation but can be enriched by other aspects/dimensions, for example the Technology Acceptance Model (Venkatesh and Bala 2008). Since the evaluation of organisational interventions is a science in itself, get an external expert/ scientist in to take over this piece of the implementation. As evaluation efforts have to be pre-planned and are partly designed as accompanying measure (Boulmetis and Dutwin 2011), kick-off the short-term and long-term evaluation planning before the implementation starts.

Long-term consequences-recommendation 5 Monitor long-term effects of the robotic device usage on the individual staff member, the work team and the organisation. As discussed before, long-term effects have not been studied in any of the 22 studies considered here. Longitudinal assessments are needed in order to uncover changes on the individual, the team and the organisational level. On the one hand, both residents and staff might need a considerable amount of time to accomodate the use of a robotic device. On the other hand, negative experiences in using robotic devices might sour the enthusiasm of the users and lead to less usage and negative reactions on the long run. These (and other) effects cannot be foreseen right from the beginning and therefore require close monitoring. Again, involving an evaluation expert/scientist might help to deploy a sound longitudinal evaluation design. 


\section{Limitations of the study and consequences for further research}

The introduction of robots in geriatric care is a rather new development in the world of work. Hence, it cannot be expected that social scientists have already extensively investigated this topic. Available studies have a pioneering position and provide already a good first insight into different aspects of the topic, most of them relying on a case study methodology going along with qualitative or smallscale quantitative data analyses. Going forward, it would be desirable to conduct larger studies that allow to compare different subgroups of staff (e.g., older versus younger nurses, certified staff versus nursing assistants). Also, longitudinal studies are needed in order to monitor the effects of the robotic usage in inpatient geriatric care over time. As has been argued in the beginning of the article, more studies that take on an Human Resources perspective help to understand the practical implications of introducing robotic devices in inpatient geriatric care.

Funding Open Access funding provided by Projekt DEAL.

Open Access This article is licensed under a Creative Commons Attribution 4.0 International License, which permits use, sharing, adaptation, distribution and reproduction in any medium or format, as long as you give appropriate credit to the original author(s) and the source, provide a link to the Creative Commons licence, and indicate if changes were made. The images or other third party material in this article are included in the article's Creative Commons licence, unless indicated otherwise in a credit line to the material. If material is not included in the article's Creative Commons licence and your intended use is not permitted by statutory regulation or exceeds the permitted use, you will need to obtain permission directly from the copyright holder. To view a copy of this licence, visit http://creativecommons.org/licenses/by/4. $0 /$.

\section{References}

American Nurses Association (2015). Code of ethics for nurses with interpretive statements. Silver Spring: Nursesbooks.org.

Bäck, I., Makela, K., \& Kallio, J. (2013). Robot-guided exercise program for the rehabilitation of older nursing home residents. $A n$ nals of Long-Term Care: Clinical Care and Aging, 21(6), 38-41.

Beedholm, K., Frederiksen, K., Skovsgaard Frederiksen, A.-M., \& Lomborg, K. (2015). Attitudes to a robot bathtub in Danish elder care: a hermeneutic interview study. Nursing \& Health Sciences, 17, 280-286.

Beer, M., Spector, B., Lawrence, P., Mills, D. Q., \& Walton, R. (1984). Managing human assets. New York: Free Press.

Bemelmans, R., Gelderblom, G., Spierts, N., Jonker, P., \& de Witte, L. (2013). Development of robot interventions for intramural psychogeriatric care. GeroPsych, 26(2), 113-120.

Bemelmans, R., Gelderblom, G., Jonker, P., \& de Witte, L. (2016). How to use robot interventions in intramural psychogeriatric care: a feasibility study. Applied Nursing Research, 30, 154-157.

Birks, M., Bodak, M., Barlas, J., Harwood, J., \& Pether, M. (2016). Robotic seals as therapeutic tools in an aged care facility: a qualitative study. Journal of Aging Research, 2, 1-7.
Boulmetis, J., \& Dutwin, P. (2011). The ABCs of evaluation: Timeless techniques for program and project managers. San Francisco: Jossey-Bass.

Boxall, P. (1992). Strategic human resources management: beginnings of a new theoretical sophistication? Human Resource Management Journal, 2(3), 60-79.

Coco, K., Kangasniemi, M., \& Rantanen, T. (2018). Care personnel's attitudes and fears toward care robots in elderly care: a comparison of data from the care personnel in Finland and Japan. Journal of Nursing Scholarship. https://doi.org/10.1111/jnu.12435.

Cowan, D. (2017). Strategic internal communication: how to build employee engagement and performance. London: KoganPage.

Darzi, L. A. (2018). Better health and care for all. The Lord Darzi review of health and care. https://www.ippr.org/research/ publications/better-health-and-care-for-all. Accessed 2 Dec 2019.

Decker, M. (2008). Caregiving robots and ethical reflection: The perspective of interdisciplinary technology assessment. AI \& Society, 22(3), 315-330.

Erebak, S., \& Turgut, T. (2018). Caregivers'attitudes toward potential robots coworkers in elder care. Cognition, Technology \& Work, 21(2), 327-336.

Gerling, K., Hebesberger, D., Dondrup, C., Körtner, T., \& Hanheide, M. (2016). Robot deployment in long-term care: Case study on using a mobile robot to support physiotherapy. Zeitschrift für Gerontologie und Geriatrie, 49, 288-297.

German Ministery of Health (2018). Zusammenfassung Pflegekräftestärkungsgesetz

Grant, M. J., \& Booth, A. (2009). A typology of reviews: an analysis of 14 review types and associated methodologies. Health Information and Libraries Journal, 26, 91-108.

Greenhalgh, T., \& Peacock, R. (2005). Effectiveness and efficiency of search methods in systematic reviews of complex evidence: audit of primary sources. BMJ, 331(7524), 1064-1065.

Gustafsson, C., Svanberg, C., \& Müllersdorf, M. (2015). Using a robotic cat in dementia care: a pilot study. Journal of Gerontological Nursing, 41(10), 46-56.

Hacker, W. (1983). Handlungsregulation. Zur aufgabenabhängigen Struktur handlungsregulierender mentaler Repräsentationen. In W. Hacker, W. Volpert, M. Cranach \& W. Hacker (Eds.), Kognitive und motivationale Aspekte der Handlung (pp. 152-174). Bern: Huber.

Hebesberger, D., Koertner, T., Gisinger, C., \& Pripfl, J. (2017). A longterm autonomous robot at a care hospital: a mixed methods study on social acceptance and experiences of staff and older adults. International Journal of Social Robotics, 9, 417-429.

Humphrey, S.E., Nahrgang, J.D., \& Morgeson, F. (2007). Integrating motivational, social, and contextual work design features: a metaanalytic summary and theoretical extension of the work design literature. The Journal of applied psychology, 92(5), 1332-1356.

Khaksar, S.M.S., Shahmehr, F., Khosla, R., \& Chu, M.T. (2017). Dynamic capabilities in aged care service innovation: the role of social assistive technologies and consumer-directed care strategy. Journal of Services Marketing. https://doi.org/10.1108/jsm-062016-0243.

Klein, B., \& Schlömer, I. (2018). A robotic shower system: Acceptance and ethical issues. Zeitschrift für Gerontologie und Geriatrie, 51, $25-31$.

Koceski, S., \& Koceska, N. (2016). Evaluation of an assistive telepresence robot for elderly healthcare. Journal of Medical Systems, 40(5), 121

Manzeschke, A., Weber, K., Rother, E., \& Fangerau, H. (2015). Ethical questions in the area of age appropriate assisting systems. Ludwigsfelde: Thiel.

Mendell, J., Palkon, D., \& Popejoy, M. (1991). Health managers' attitudes toward robotics and artificial computer intelligence: an empirical investigation. Journal of Medical Systems, 15(3), 197-204. 
Mlekus, L., Ötting, S., \& Maier, G. W. (2018). Psychologische Arbeitsgestaltung digitaler Arbeitswelten. In G. W. Maier, G. Engels \& E. Steffen (Eds.), Handbuch Gestaltung digitaler und vernetzter Arbeitswelten. Heidelberg, Berlin, New York: Springer.

Moyle, W., Bramble, M., Jones, C., \& Murfiled, J. (2016). Care staff perceptions of a social robot called Paro and a look-alike Plush Toy: a descriptive qualitative approach. Aging \& Mental Health, 22(3), 330-335.

Nikolakis, N., Maratos, V., \& Makris, S. (2019). A cyber physical system (CPS) approach for safe human-robot collaboration in a shared workplace. Robotics and Computer Integrated Manufacturing, 56, 233-243.

Pammolli, F., Riccaboni, M., \& Magazzini, L. (2012). The sustainability of European health care systems: Beyond income and aging. European Journal of Health Economics, 13, 623-634.

Peronard, J.-P. (2013). Readiness for living technology: a comparative study of the uptake of robot technology in the Danish health-care sector. Artificial Life, 19, 421-436.

Robinson, H., MacDonald, B., Kerse, N., \& Broadbent, E. (2013). Suitability of healthcare robots for a dementia unit and suggested improvements. The Journal of Post-Acute and Long-Term Care Medicine, 14(1), 34-40.

Robinson, H., Broadbent, E., \& MacDonald, B. (2016). Group sessions with Paro in a nursing home: Structure, observations and interviews. Australasian Journal on Ageing, 35(2), 106-112.

Rodeschini, G. (2011). Geotechnology: A new kind of care for aging? An analysis of the relationship between older people and technology. Nursing Heath Science, 13, 521-528.

Savage, G. T., Nix, T. W., Whitehead, C. J., \& Blair, J. D. (1991). Strategies for assessing and managing organizational stakeholder. The Executive, 5(2), 61-75.

Shin, J., Rusakov, A., \& Meyer, B. (2016). SmartWalker: An intelligent robotic walker. Journal of Ambient Intelligence and Smart Environments, 8(4), 383-398.

Steil, J. J., \& Maier, G. W. (2018). Kollaborative Roboter: universale Werkzeuge in der digitalisierten und vernetzten Arbeitswelt. In G. W. Maier, G. Engels \& E. Steffen (Eds.), Handbuch Gestaltung digitaler und vernetzter Arbeitswelten. Heidelberg, Berlin, New York: Springer.

Takayanagi, K., Kirita, T., \& Shibata, T. (2014). Comparison of verbal and emotional responses of elderly people with mild/moderate dementia and those with severe dementia in resonses to seal robot PARO. Frontiers in Aging Neuroscience, 6, 256.

Trist, E., \& Bamforth, K. (1951). Some social and psychological consequences of the longwall method of coal getting. Human Relations, 4, 3-38.

UK Government (2019). Care robots could revolutionise UK care system and provide staff extra support. https://www.gov.uk/ government/news/care-robots-could-revolutionise-uk-caresystem-and-provide-staff-extra-support. Accessed 12 Dec 2019.

Venkatesh, V., \& Bala, H. (2008). Technology acceptance model 3 and a research agenda on interventions. Decision Sciences, 39(2), 273-315.

Wright, J. (2018). Tactile care, mechanical Hugs: Japanese caregivers and robotic lifting devices. Asian Anthropology, 17(1), 24-39.

Zwijsen, S. A., Niemeijer, A.R., \& Hertogh, C.M. (2011). Ehtics of using assistive technology in the care for community-dwelling elderly people: an overview of the literature. Aging \& Mental Health, 15(4), 419-427.

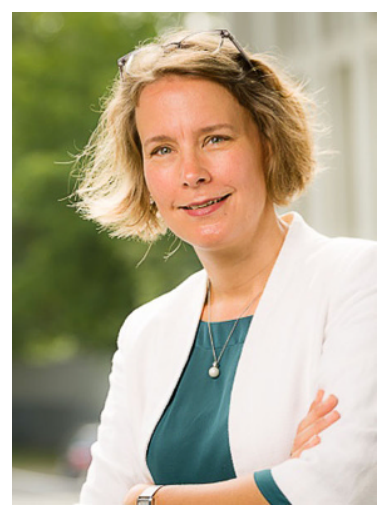

Prof. Dr. Anne-Katrin Haubold ist Professorin für Personalmanagement an der HTW Dresden und CoHead der an der HTW angesiedelten Forschungsgruppe "Human Factors and Resources".

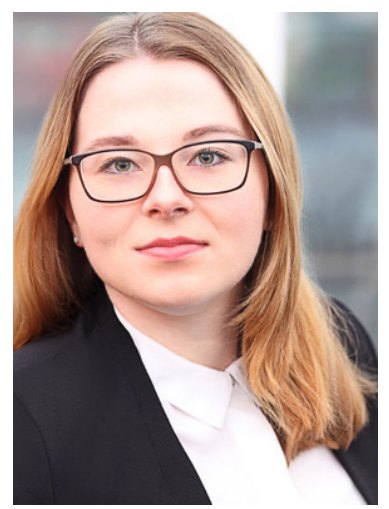

Lisa Obst ist seit 2018 wissenschaftliche Mitarbeiterin und Doktorandin an der HTW Dresden. Sie hat International Business (B.A.) und Management mittelständischer Unternehmen (M. A.) an der HTW Dresden studiert.

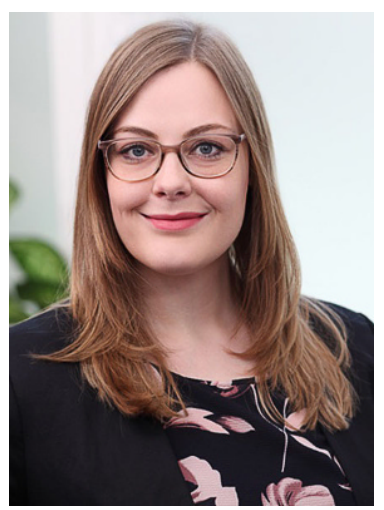

Franziska Bielefeldt ist seit 2018 wissenschaftliche Mitarbeiterin und Doktorandin an der HTW Dresden. Sie hat Psychologie (B.Sc.) und Human Performance in socio-technical systems (M.Sc.) an der TU Dresden studiert. 